\title{
THE
}

\section{Adolescents and Sexual Risk-Taking: The Interplay of Constraining Relationship Beliefs, Healthy Sex Attitudes, and Romantic Attachment Insecurity}

Hans Saint-Eloi Cadely

University of Rhode Island, hsainteloicadel@uri.edu

Vanessa Finnegan

Erica C. Spears

Jennifer L. Kerpelman

Follow this and additional works at: https://digitalcommons.uri.edu/hdf_facpubs

The University of Rhode Island Faculty have made this article openly available.

Please let us know how Open Access to this research benefits you.

This is a pre-publication author manuscript of the final, published article.

Terms of Use

This article is made available under the terms and conditions applicable towards Open Access Policy Articles, as set forth in our Terms of Use.

\section{Citation/Publisher Attribution}

Saint-Eloi Cadely, H., Finnegan, V., Spears, E., \& Kerpelman, J. L. (2020). Adolescents and sexual risktaking: The interplay of constraining relationship beliefs, healthy sex attitudes, and romantic attachment insecurity. Journal of Adolescence, 84, 136-148. doi: 10.1016/j.adolescence.2020.08.010 Available at: https://doi.org/10.1016/j.adolescence.2020.08.010

This Article is brought to you for free and open access by the Human Development and Family Science at DigitalCommons@URI. It has been accepted for inclusion in Human Development and Family Science Faculty Publications by an authorized administrator of DigitalCommons@URI. For more information, please contact digitalcommons-group@uri.edu. 
Adolescents and Sexual Risk-Taking: The Interplay of Constraining Relationship Beliefs, Healthy Sex Attitudes, and Romantic Attachment Insecurity

\author{
Hans Saint-Eloi Cadely \\ Vanessa Finnegan \\ Erica C. Spears \\ Jennifer L. Kerpelman \\ University of Rhode Island \\ Auburn University \\ University of North Texas Health Science Center
}

Author Note

Hans Saint-Eloi Cadely, Department of Human Development and Family Studies, University of Rhode Island; Vanessa Finnegan, Department of Human Development and Family Studies, Auburn University; Erica C. Spears, School of Public Health, University of North Texas Health Science Center; Jennifer L. Kerpelman, Department of Human Development and Family Studies, Auburn University.

This study was supported through grants from the U.S. Department of Health and Human Services, Office of Planning Research and Evaluation (90OJ2017) and the Alabama Department of Child Abuse and Neglect Prevention/Children's Trust Fund (CFFS 2006-301).

Correspondence concerning this article should be addressed to Hans Saint-Eloi Cadely, Department of Human Development and Family Studies, University of Rhode Island, Kingston, RI 02881. E-mail: hsainteloicadel@uri.edu. 


\begin{abstract}
Introduction: Although sexual exploration during adolescence may be perceived as normative, many adolescents who are sexually active are likely to engage in risky sexual behaviors detrimental to their well-being. The present study examined the influence of insecure attachment (anxious and avoidant dimensions), healthy sex attitudes, and constraining relationship beliefs on the following sexual risk indicators: age at first sex, number of sexual partners, condom use, length of time knowing sexual partners, seriousness of relationship, and frequency of sex.

Methods: Cross-sectional data from two cohorts recruited one year apart for a five-year project were analyzed. Adolescents were public high school students from a Southern state in the USA (cohort 1: $N=878,51.1 \%$ females, $M=16.50$ years old; cohort $2: N=759,46.9 \%$ females, $M=$ 15.78 years old).
\end{abstract}

Results: Across both cohorts, healthy sex attitudes were related to having sex for the first time at an older age, having less sexual partners in a lifetime, and knowing one's sexual partner longer. High scores on the avoidant attachment dimension were related to less commitment to the relationship. This dimension also was related to holding lower scores on healthy sex attitudes, which in turn was related to having more sexual partners and knowing one's sexual partner for a shorter time. Although not replicated, higher endorsement of constraining relationship beliefs was associated with inconsistent condom use and greater sex frequency.

Conclusion: Findings suggests that attachment insecurity, healthy sex attitudes, and constraining relationship beliefs work together to influence adolescent sexual risks.

Keywords: adolescence, constraining relationship beliefs, healthy sex attitudes, insecure attachment, sexual risk indicators 


\section{Adolescents and Sexual Risk-Taking: The Interplay of Constraining Relationship Beliefs, Healthy Sex Attitudes, and Romantic Attachment Insecurity}

Although moral debate continues, sexual exploration during adolescence is considered normative (Tolman \& McClelland, 2011) with over 40\% of adolescents (ages 15-19 years old) during the period of 2011-2015 having had vaginal sexual intercourse (Centers for Disease Control and Prevention, 2018). What remains a concern for scholars of adolescent development and practitioners who work with adolescents is sexual risk-taking. Examples of sexual risktaking include beginning sexual activity in early adolescence, having multiple sexual partners, engaging in a high frequency of sexual activity, and inconsistent condom use (e.g., Costa et al., 2017; Feeney et al., 2000; Letcher \& Slesnick, 2014; Tracy et al., 2003). These risks can affect adolescents' physical and emotional health and the quality of their future adult relationships. For example, Kahn and Halpern (2018) in their examination of $7^{\text {th }}$ through $12^{\text {th }}$ graders found that having fewer sexual partners was related to lower likelihood of being diagnosed with a sexually transmitted infection (STI), lower odds of unplanned pregnancies, and higher odds of better romantic relationship quality in young adulthood. Understanding variability in sexual risk-taking among high school-age adolescents who have had vaginal sexual intercourse is the primary focus of the current study.

Scholarly efforts have begun to identify factors that exacerbate or mitigate adolescents' risky sexual activity; however, much of the research has focused on young adult (college) populations (Olmstead, 2020). Past research indicates that adolescents' romantic attachment insecurity, as well as their attitudes about sex and beliefs about relationships may be particularly important for understanding their risky sexual engagement (McElwain et al., 2015; Mitchell et al., 2004; Gebhardt et al., 2003; Tracy et al., 2003). Although romantic attachment insecurity and 
attitudes about sex have been shown to influence cumulative sexual risk-taking (McElwain et al., 2015), it remains to be seen how these factors along with adolescents' beliefs about relationships collectively and uniquely influence different aspects of sexual risk-taking. The present study used a test-replication approach to address this gap in the literature. Specifically, romantic attachment insecurity, relationship beliefs, and attitudes about sex were examined together to ascertain their relative influence on distinct indicators of adolescents' sexual risk-taking. We tested the model with two separate cohorts of sexually experienced adolescents, where replication of findings across cohorts increased confidence in the results.

\section{Theoretical Frameworks for Understanding Adolescents' Sexual Risk-Taking Problem Behavior Theory and the Theory of Planned Behavior}

Problem Behavior Theory (Jessor, 1991) offers a risk/protective factor model (see Manning et al., 2005) to examine influences on different indicators of sexual risk. According to Problem Behavior Theory, in order to reduce risks, it is crucial to understand factors associated with greater probability of risky sexual engagement (Bingham \& Crockett, 1996; Jessor, 1991). Problem Behavior Theory also suggests that cognitive factors may serve as predictors of later engagement in risk behaviors (Jessor, 1991). Thus, we integrate Problem Behavior Theory with the Theory of Planned Behavior to consider cognitive factors associated with higher or lower sexual risk-taking among sexually experienced adolescents. Theory of Planned Behavior offers a social cognitive perspective of health behavior motivation and indicates that perceptions and attitudes affect individuals' motivations and subsequent engagement in behavior (Ajzen, 1985; Stevens et al., 2019). Cognitive factors expected to be associated with greater sexual risk-taking include adolescents' romantic attachment insecurity (i.e., orientation toward relationship intimacy; Brennan et al. 1998), constraining relationship beliefs (i.e., unrealistic beliefs about 
romantic relationships and mate selection; Cobb et al., 2003; Larson, 1992), and attitudes about sexual behavior (i.e., what makes sexual activity healthier; Gardner et al., 2004). Past research points to the importance of assessing beliefs and attitudes about relationships and sex, as well as romantic attachment insecurity to understand risk-taking in adolescence (Kerpelman et al., 2009, 2010; Kim \& Miller, 2020; McElwain et al., 2015; McNeill et al., 2020; Olmstead, 2020; SaintEloi Cadely et al., 2018). The present study builds on this literature by examining whether such insecurities, beliefs, and attitudes work together to explain variability in different indicators of sexual risk-taking.

The sexual risk indicators assessed in the present study were identified from prior research and include age at first sex, number of sexual partners, condom use, length of knowing sexual partner, seriousness of relationship, and frequency of sex (e.g., Bogaert \& Sadava, 2002; Feeney et al., 2000; Kahn \& Halpern, 2018; Letcher \& Slesnick, 2014; Tracy et al., 2003). Such risks are shown to be related to adverse outcomes. For instance, adolescents and young adults who become sexually active at a young age and/or have multiple sexual partners are more likely to be diagnosed with an STI (Kahn \& Halpern, 2018), engage in behaviors that increase the likelihood for an STI diagnosis (Cubbins \& Tanfer, 2000), experience intimate partner violence (Manning et al., 2014), or experience an unintended pregnancy (Prendergast et al., 2019). Risks of unplanned pregnancies, STIs, and/or HIV diagnosis also increases among adolescents and young adults who fail to use a condom during sex or who have sex before being committed to their partner (Claxton \& van Dulmen, 2013; Misovich et al., 1997). A high frequency of sexual intercourse during adolescence and young adulthood also increases the likelihood for unprotected sex (Strachman \& Impett, 2009). Moreover, adolescents who are nonexclusive with their sexual partners may be more likely to experience negative mental health outcomes such as 
depression and low self-esteem (Claxton \& van Dulmen, 2013; Manning et al., 2014). Sexual non-exclusivity also shows positive associations with gambling, substance use, and truancy (Fortunato et al., 2010).

\section{Insecurities, Beliefs and Attitudes}

Romantic Attachment Insecurity. Adolescents' romantic relationships have been documented to be distinct and important contributors to adolescent development (Collins, 2003; Collins et al., 2009). Romantic attachment in adolescence evolves from earlier attachment security with caregivers and is further shaped by close relationship experiences in childhood and adolescence (Kochendorfer \& Kerns, 2017; 2020; Jones et al., 2018; Pittman et al., 2011; Roisman et al., 2009). Adult Attachment Theory holds that individuals may have trouble forming intimacy in their romantic relationships due to worries or discomfort with such unions. Individuals may devalue or avoid intimacy out of fear of rejection or losing their independence (i.e., avoidant attachment) or they may become enmeshed in the relationship to the point of overdependence on their partner (i.e., anxious attachment) (Bartholomew, 1990; Bartholomew \& Horowitz, 1991; Brennan et al., 1998). Recent research shows that attachment insecurity is associated with a broad range of romantic relationship problems in early adulthood (Muetzelfeld et al., 2020), but develops well before that time (Pittman et al., 2011). Prior to adulthood, anxious and avoidant attachment affect how adolescents think about sex (Davis et al., 2004; McElwain et al., 2015; Schachner \& Shaver, 2004) which, in turn, is associated with their sexual engagement (Feeney et al., 1999; 2000; Tracy et al., 2003). Romantic attachment insecurity also has direct links to various sexual behaviors seen in adolescence, including frequent sexual activity (Tracy et al., 2003) and low condom use (Feeney et al., 1999; 2000). 
Research indicates that anxious and avoidant attachment associate differently with sexual behaviors, but these findings are not always consistent across studies. Both Schachner and Shaver (2004), and Tracy et al. (2003) reported that adolescents with higher levels of avoidant or anxious attachment gave different reasons for engaging in sex, with avoidant adolescents doing so to lose their virginity, and anxious adolescents doing so to express love and to feel emotionally valued by their partners. Tracy et al. (2003) also found that adolescents with higher avoidance were less likely than secure or anxious adolescents to have ever had sexual intercourse, and they reported to have less sexual experience relative to secure and anxious adolescents.

In a small sample of primarily white and African American heterosexual adolescent couples, Letcher and Slesnick (2014) showed that adolescents with higher attachment anxiety participated in greater frequency of risky sexual behaviors (e.g., having more sexual partners and less condom use) compared to adolescents with lower attachment anxiety; no association was found between sexual risk-taking and attachment avoidance. In contrast, a study with a large sample of Canadian adolescents ages 16-20 found that adolescent sexual risk-taking behaviors (i.e., sexual intercourse at a young age and having more sexual partners) were predicted by attachment avoidance but not associated with attachment anxiety (Lemelin et al., 2014). Feeney et al. (2000) found that avoidant attachment was positively associated with consistent condom use among late adolescent males. Finally, multiple studies with adolescent and young adult samples show that greater attachment anxiety is associated with less frequent condom use (Feeney et al., 1999, 2000; Kim \& Miller, 2020; MacDonald et al., 2016; Strachman \& Impett, 2009); however Bogaert and Sadava, (2002) found that anxious attachment was associated with greater condom use as well as earlier sexual debut, and more lifetime sexual partners. 
Discrepancies across studies may be due to different instruments used to measure attachment and demographic differences among the samples. Based on findings across the research conducted, we hypothesized that greater attachment anxiety would be related to greater risk across different indicators of sexual risk-taking, especially frequency of sexual activity and inconsistent condom use, whereas, higher levels of attachment avoidance would be associated with risk-taking in areas of having less knowledge of and less emotional connection to a sexual partner (Hypothesis 1).

Constraining Relationship Beliefs. Just as romantic attachment insecurity has far reaching effects on adolescents' lives, beliefs about romantic relationships that take shape during early adolescence set a foundation for future relationship trajectories that continue to influence relationship experiences across the lifespan. For instance, research has demonstrated a compelling link between characteristics of relationship quality during adolescence and subsequent relationship quality in young adulthood (Madsen \& Collins, 2011). Few studies, however, have addressed adolescents' beliefs about relationships and their relative influence on adolescents' sexual activity and romantic relationships (e.g., Gebhardt et al., 2003; Ott et al., 2006).

Adolescents and young adults hold beliefs about relationship characteristics, including expectations for a good relationship, and how partners behave in romantic relationships (Driesmans et al., 2016; Ma et al., 2014; Montgomery, 2005; Sprecher \& Metts, 1999). Notably, development of scripts for romantic relationships and potential relationship partners take prominence during adolescence (Furman \& Simon, 1999). In Western culture, constraining relationship beliefs often "idealize" the notion of romantic relationships (Larson, 1992). For example, beliefs such as "love is enough to sustain a relationship" may begin to take shape 
during adolescence (Driesmans et al., 2016) and influence partner selection during young adulthood (Cobb et al., 2003).

In a recent study of relationship beliefs among Belgian adolescent girls (ages 11-14), researchers illustrated that adolescents are likely to hold constraining relationship beliefs, such as the belief that one's true love will be nearly perfect (Driesmans et al., 2016). However, few studies address connections between beliefs about relationships and sexual behaviors. One study addressing these connections among ninth graders found that intimacy was valued the most, followed by status, then pleasure as motivation for sexual behavior (Ott et al., 2006). The motives of having sex to build intimacy and to express love also show associations with unprotected sex among adolescents (Gebhardt et al., 2003), and casual sexual partnerships are associated with adolescents' hopes or expectations that such partnerships may lead to more conventional dating relationships (Manning et al., 2006). Consistent with theory and limited past research, we anticipated that constraining relationship beliefs would predict greater risk across the different indicators of sexual risk-taking (Hypothesis 2).

Healthy Sex Attitudes. Problem Behavior Theory emphasizes the importance of addressing factors that minimize the likelihood of risk (Jessor, 1991). By considering sexuality as a normative and essential aspect of development, it is important to understand adolescents' management of the inherent risks of sexual activity (Chilman, 1990; Tolman \& McClelland, 2011). Furthermore, the Theory of Planned Behavior suggests that adolescents' attitudes about sexual activity affects their intentions and subsequent sexual engagement (McEachan et al., 2011). Thus, holding healthy attitudes about sex, attitudes that emotional connection and having greater maturity should precede sexual engagement, may serve as a protective factor against sexual risk-taking activities such as having multiple sexual partners and/or not using 
contraceptives during sex (Chilman, 1990). Prior research indicates that such attitudes influence sexual decisions and have positive implications for adolescents' well-being (Harden, 2014; McElwain et al., 2015).

Moreover, Bersamin et al. (2006) found that early to middle adolescents' endorsements of negative sexual health expectations (e.g., getting a sexually transmitted infection) negatively predicted engagement in oral sex and vaginal intercourse, and McElwain et al. (2015) indicated that adolescents' endorsement of healthy sex attitudes (e.g., waiting to have sex until one is ready) was related to lower cumulative sexual risk-taking. Finally, a meta-analysis that included studies with samples of adolescents and adults, showed that individuals' beliefs in regard to perceptions of others' thinking of how one should engage in a behavior were associated with their intentions to engage in safer sex behaviors (McEachan et al., 2011). Thus, if adolescents believe it is normative to wait until one is emotionally connected or older before having sex, they are less likely to take sexual risks. Based on prior research and the Theory of Planned Behavior, we expected that holding healthy sex attitudes would be associated with lower risk across different indicators of sexual risk-taking (Hypothesis 3).

Finally, given that romantic attachment security evolves from earlier childhood attachment to caregivers (Connolly \& McIsaac, 2011; Pittman et al., 2011; Roisman, 2009), and beliefs and attitudes about romantic relationships and sexual behavior actively take shape during adolescence (Driesmans et al., 2016; Ma et al., 2014; McElwain et al., 2015; Montgomery, 2005), it may be that romantic attachment insecurity also predicts sexual risk-taking through associations with relationship beliefs or attitudes about sex. Furthermore, Problem Behavior Theory posits that risk and protective factors work together to influence risk-taking (Bingham \& Crockett, 1996; Jessor, 1991), and prior research shows associations among relationship beliefs 
and romantic attachment insecurity (Stackert \& Bursik, 2003; Turner \& Langhinrichsen-Rohling, 2011), as well as between sex attitudes and romantic attachment insecurity (Feeney et al., 2000; McElwain et al, 2015). Thus, we expected that attachment avoidance and anxiety would show associations with constraining relationship beliefs and healthy sex attitudes, which in turn would predict the different indicators of sexual risk-taking (Hypothesis 4).

\section{The Present Study}

The current study examined how romantic attachment insecurity, constraining relationship beliefs, and healthy sex attitudes work together as risk/protective factors to explain sexual risk-taking among adolescents who have experienced vaginal sexual intercourse (see Figure 1). In our first three hypotheses, we tested direct associations among romantic attachment avoidance and anxiety, constraining relationship beliefs and healthy sex attitudes, and the different indicators of sexual risk-taking. We also examined in our fourth hypothesis whether the romantic attachment dimensions show indirect associations with the sexual risk indicators through constraining relationship beliefs and healthy sex attitudes.

\section{Method}

Data from two cohorts were analyzed for this test-replication study. The cohorts were recruited one year apart, for a five-year evaluation project. Written assent/consent for both cohorts was provided by adolescents/parents for data collection. Data were collected during regular school hours from students in public high school health classes across a Southern state in the United States. Only pre-test data (data collected prior to the intervention) were used.

\section{Participants and Procedure}

\section{Cohort 1}


The first cohort consisted of 2,577 adolescents recruited during the third year of the project. Adolescents were dropped from this study if they had not had vaginal sexual intercourse $(n=1,331)$, were missing data across all the study variables $(n=284)$, had responses categorized as inconsistent $(n=55)$, or had sex prior to the adolescent developmental period $(n=29)$; adolescence is defined as beginning at the age of 10 (American Psychological Association, 2002).

The final sample was composed of predominately $10^{\text {th }}$ graders $(58 \% ; N=878$ adolescents). Approximately $35 \%$ were 16 years of age $(M=16.50 ; S D=1.06), 51.1 \%$ were females, and more than half received free/reduced lunch (52.6\%). Just under half of the adolescents identified as European-Americans (46.2\%); the remainder identified as an ethnic minority (44\% African Americans, 4.2\% Hispanics/Latinos, 2.2\% Native Americans, 0.8\% Asian Americans, and 2.2\% other ethnic backgrounds).

\section{Cohort 2}

The second cohort $(N=1,942)$ was recruited during the fourth year of the project. As in cohort 1 , adolescents who had not had vaginal sexual intercourse $(N=1,051)$, adolescents who were missing data across all variables of interests to this study $(n=66)$, adolescents whose data on these variables were labeled as inconsistent $(n=29)$, and adolescents who had sex at age nine or younger $(n=37)$ were removed from further analyses.

The final sample for cohort 2 consisted of 759 adolescents who were predominately $10^{\text {th }}$ graders $(55.7 \%)$ and approximately $39 \%$ were 16 years old $(M=15.78 ; S D=.95)$. Just under half of the sample was female (46.9\%) and more than half identified as African Americans (60.7\%); the remainder of the sample identified as European-Americans (31.4\%), 
Hispanics/Latinos (3.3\%), Native Americans (0.7\%), Asian Americans (0.3\%), and 3.2\% other ethnic backgrounds. The majority received free/reduced lunch (65.5\%).

\section{Measures for both Cohorts}

\section{Insecure Romantic Attachment}

Insecure romantic attachment was assessed with 18 items from the Experiences in Close Relationships Scale (Brennan et al., 1998), with nine items for avoidant attachment (e.g., "I get uncomfortable when a romantic partner wants to be very close"), and nine items for the anxious attachment (e.g., "My desire to be close sometimes scares people away"). Items were rated on a five-point scale ranging from 1 (strongly disagree) to 5 (strongly agree). Based on an independent sample, correlations between the selected items and the full subscale were .97 for both subscales (Kerpelman et al., 2012). Cronbach alphas for cohorts 1 and 2 were .75 and .74, respectively for avoidance, and .80 and .82 respectively for anxiety. A composite score based on the mean of the items for each attachment dimension was created; higher scores indicated greater romantic attachment insecurity.

\section{Healthy Sex Attitudes}

Seven items from Gardner et al. (2004) were used to assess healthy sex attitudes. The selected items assessed waiting to have sex (e.g., "In future dating relationships, I intend to wait to have sex until I really feel emotionally connected with my partner”) and general attitudes regarding sexual intercourse (e.g., "It is risky for young teens to have sex"). Items were rated on a five-point scale ranging from 1 (strongly disagree) to 5 (strongly agree) $(\alpha=.69$ for cohort $1 ; \alpha$ $=.78$ for cohort 2 ). A composite score based on the mean of the items was created. Higher scores indicated greater healthy sex attitudes.

\section{Constraining Relationship Beliefs}


Constraining relationship beliefs were assessed with eight items from the Attitudes and Romance Mate Selection Scale (Cobb et al., 2003). The selected items assessed the beliefs that there is one person meant for one to marry (e.g., "There is one true love out there who is right for me to marry") and love is enough to sustain a relationship (e.g., "In the end, our feelings of love for each other should be enough to sustain a happy marriage"). Items were rated on a five-point scale ranging from 1 (strongly disagree) to 5 (strongly agree) $(\alpha=.76$ for cohort $1 ; \alpha=.74$ for cohort 2). A composite score based on the mean of the items was calculated. Higher scores indicated more endorsement of constraining relationship beliefs.

\section{Sexual Risk Indicators}

The following five items served as sexual risk indicators: (a) Age at first sex ("How old were you when you first had sexual intercourse?”); Responses ranged from 10-16 years old or older, (b) Number of sexual partners ("During your life, with how many people have you had sexual intercourse?"; 1 (one person) - 5 (five people or more)), (c) Condom use ("In the last month, how much of the time did you or your sexual partner use a condom (rubber) when you had sexual intercourse?"; 1 (None of the times) - 5 (Always)), (d) Relationship length ("How long did you know the person with whom you most recently had sexual intercourse?"; 1 (Knew the person less than a week) - 5 (Knew the person for more than six months)), and (e) Seriousness of relationship ("How serious is the relationship with the person with whom you most recently had sexual intercourse?"; 1 (We are not dating) - 4 (We are dating seriously and only each other)). Participants in cohort 2 also rated one item assessing frequency of intercourse in the last 30 days ("How often did you have sexual intercourse during the last 30 days?"; 1 (less than once per week) - 4 (four or more times per week)).

\section{Demographic Covariates}


Gender, race, age, and socioeconomic status (SES) were examined as covariates given their associations with risky sexual behaviors. Past studies show that adolescents who engage in risky sexual behaviors are more likely to be younger, male, and coming from an ethnic minority background and/or from a lower SES household (Harris et al., 2002; Manning et al., 2000, 2005, 2006). Thus, these demographics were included as covariates in the present study. Age was coded in years; all other demographic variables were dichotomized $($ Gender: $0=$ male, $1=$ female; Race: 0 = European-American, 1 = Minority; Free/reduced lunch $($ proxy for socioeconomic status): $0=N o, 1=Y e s)$.

\section{Plan of Analysis}

Preliminary analyses (i.e., means, standard deviations, zero-order correlations, chisquares, and t-tests) were conducted in SPSS Version 26 (IBM Corp, 2018). Structural equation modeling (SEM) with indirect effects tested the study hypotheses using MPLUS Version 7 (Muthén \& Muthén, 1998-2012). All sexual risk indicators were treated as individual variables in the model predicted by the composite variables of anxious and avoidant attachment, healthy sex attitudes, and constraining relationship beliefs while controlling for demographic covariates. Pathways with indirect effects were included in the model to examine whether insecure romantic attachment predicted any of the sexual risk indicators through healthy sex attitudes or constraining relationship beliefs. The same procedure was conducted for both cohorts (see Figure 1). Given that multiple variables were being controlled for in both models, pathways at $p<.10$ are discussed in the results section.

Full Information Maximum Likelihood (FIML) was used to manage missing data. Model fit for the SEM model was determined by a non-significant chi-square $\left(\chi^{2}\right)$, a comparative fit index (CFI) between $.90-1.00$ (Bentler \& Bonnett, 1980), a root mean square error of 
approximation (RMSEA) of .10 or lower (Harlow, 2014), and a standardized root mean square residual (SRMR) of .10 or lower (Kline, 2016).

\section{Results}

Intercorrelations across the study variables for both cohorts are presented in Table 1. Mean and percentage differences across cohorts in demographics, predictors, and outcomes are identified in Table 2. Compared to cohort 1, adolescents in cohort 2 were more likely to have received free/reduced lunch, to identify as part of an ethnic minority group, and to be younger. Cohort 2 adolescents also endorsed less constraining relationship beliefs, less healthy sex attitudes, and reported lower scores on anxious attachment relative to cohort 1 adolescents. Regarding sexual risk indicators, adolescents in cohort 2 had sex for the first time at a younger age, had less serious relationships, and had more sexual partners compared to cohort 1 adolescents.

In both cohorts, the $\chi^{2}$ of the SEM models were significant (Cohort $1: \chi^{2}=11.78, p<$ .001 ; Cohort $\left.2: \chi^{2}=16.91, p<.001\right)$, but this was expected as the $\chi^{2}$ is often significant in large samples (Kline, 2016). Although the RMSEAs were slightly above the cutoff for an acceptable model fit $($ Cohort 1: RMSEA $=.11,90 \%$ confidence interval $[\mathrm{CI}]=[.06, .17]$; Cohort 2: RMSEA $=.14,90 \%[\mathrm{CI}]=[.09, .21])$, the CFI and SRMR indicated that the model fit the data well $($ Cohort 1: CFI $=.99, \mathrm{SRMR}=.01 ;$ Cohort 2: $\mathrm{CFI}=.98, \mathrm{SRMR}=.01)$. Coefficients for the direct paths are found in the top half of the tables and coefficients for the testing of the indirect paths are found in the bottom half of the tables (see Tables $3 \& 4$ ).

\section{Fully and Partially Replicated Findings}

Across the test and replication samples, healthy sex attitudes were related to having sex for the first time at an older age, a lower number of lifetime sexual partners, and knowing one's 
sexual partner longer. Avoidant attachment was associated directly with less serious relationships in both cohorts; cohort 2 also had an indirect association through constraining relationship beliefs, where a high score on the avoidant dimension was related to a low endorsement of constraining relationship beliefs $(B$ (unstandardized path coefficient $)=-.32, S E$ (standard error) $=.04, \beta$ (standardized path coefficient $)=-.30, p<.001)$, which was then associated with less commitment to the relationship. Furthermore, in both cohorts, attachment avoidance predicted healthy sex attitudes which then predicted the number of lifetime sexual partners and the length of time knowing the sexual partner. Specifically, a high score on attachment avoidance was related to a low endorsement of healthy sex attitudes (Cohort 1: $B=-.13, S E=.03, \beta=-.13, p<$ .001 . Cohort 2: $B=-.09, S E=.04, \beta=-.08, p<.05)$, which in turn was related to knowing one's sexual partner for a shorter time and having a high number of sexual partners. In cohort 2, avoidant attachment also showed a direct and negative association with length of time knowing the partner. In addition, a higher score on anxious attachment was related to lower condom use, directly in cohort 2 and indirectly through constraining relationship beliefs in cohort 1 . In other words, for cohort 1 , a high score on the anxious dimension was related to a high score on constraining relationship beliefs $(B=.10, S E=.03, \beta=.12, p<.01)$, which was then related to less condom use. Finally, avoidant attachment predicted having sex for the first time at a younger age, directly in cohort 2 , and indirectly through lower healthy sex attitudes in cohort 1. Specifically, for cohort 1 , a high score on the avoidant dimension was related to a lower endorsement of healthy sex attitudes, which in turn was related to having sex for the first time at a younger age (see Tables $3 \& 4)$.

\section{Nonreplicated Findings}

\section{Cohort 1}


Adolescents with high scores on anxious attachment had their first sexual experience at a younger age. Furthermore, adolescents who endorsed constraining relationship beliefs were less likely to use a condom during their recent sexual encounters. However, a high score on avoidant attachment was directly related to greater likelihood of condom use, as well as indirectly related to condom use through lower scores on constraining relationship beliefs. Thus, high avoidant attachment was related to lower constraining relationship beliefs $(B=-.29, S E=.04, \beta=-.28, p$ $<.001$ ), which were then related to more condom use during sex (see Table 3).

\section{Cohort 2}

Adolescents with higher constraining relationship beliefs were more likely to be in a serious relationship. Furthermore, higher anxious attachment was related positively to constraining relationship beliefs $(B=.21, S E=.03, \beta=.23, p<.001)$ which in turn were related to being in a more serious relationship. However, higher avoidant attachment was related to lower constraining relationship beliefs which in turn were related to being in a less serious relationship (see Table 4).

\section{Extension of the Model}

A second model was fit for cohort 2 adding frequency of sex as a sexual risk indicator. Healthy sex attitudes were negatively associated with sex frequency $(B=-.30, S E=.05, \beta=-.25$, $p<.001$ ), whereas higher constraining relationship beliefs were related to having sex more often $(B=.10, S E=.05, \beta=.08, p<.05)$. In addition, higher anxious attachment was related to higher constraining relationship beliefs $(B=.21, S E=.03, \beta=.23, p<.001)$, which in turn were associated with more frequent sex. Finally, higher avoidant attachment was negatively associated with healthy sex attitudes $(B=-.09, S E=.04, \beta=-.08, p<.05)$, which in turn were related to higher sex frequency; however, higher avoidant attachment was related to lower constraining 
relationship beliefs $(B=-.32, S E=.04, \beta=-.30, p<.001)$, which were associated with lower sex frequency.

\section{Support of Hypotheses}

Varying support was found across the four study hypotheses. The first hypothesis received some support in each of the cohorts, but the patterns were not consistently replicated. Specifically, attachment avoidance was related to less commitment to one's sexual partner across both cohorts but was related to less time knowing the partner only for the second cohort. Additionally, attachment anxiety predicted greater risk in having sex for the first time at a younger age in cohort 1 , and less condom use during sex in cohort 2. Consistent with the second hypothesis, constraining relationship beliefs were related to less condom use in cohort 1 and more frequency of sex in cohort 2. Strongest support was found for the third hypothesis. Across both cohorts, healthy sex attitudes were related to being older when having sex for the first time, having fewer sexual partners in a lifetime, and knowing one's sexual partner for a longer time. Healthy sex attitudes also were related to a lower frequency of sex for the second cohort. Lastly, some support, including replicated paths, was found for the fourth hypothesis. Across both cohorts, indirect associations through healthy sex attitudes were shown in the relationship between attachment avoidance and number of sexual partners and between this predictor and length of time knowing the sexual partner. For cohort 1, both attachment dimensions were indirectly related to condom use through constraining relationship beliefs. High scores on the avoidant dimension also worked through healthy sex attitudes in predicting age at first sex. For cohort 2 , both attachment dimensions predicted constraining relationship beliefs, which in turn predicted commitment to one's sexual partner and frequency of sex. Lastly, high scores on the 
avoidant dimension predicted lower healthy sex attitudes which predicted greater frequency of sex.

\section{Discussion}

Guided by theories of problem behavior (Jessor, 1991), planned behavior (Ajzen, 1985), and romantic attachment (Brennan et al., 1998) findings of the current study add to the limited research showing links between adolescents' insecurities, beliefs and attitudes, and their risky sexual engagement. A unique feature of this study is the use of a test-replication approach to validate the findings. Replicated findings include the risk factor of avoidant attachment and its direct association with being in a less serious sexual relationship, and the protective factor of holding healthy sex attitudes and its direct association with lower sexual risk across multiple indicators. The protective nature of healthy sex attitudes is also shown in its intervenience in associations between attachment avoidance with number of sexual partners and length of knowing one's sexual partner. Other findings supported in one of the cohorts, while less robust, are valuable for understanding how adolescents' insecurities, beliefs and attitudes matter for sexual risk-taking. Collectively, the findings support the integration of Problem Behavior Theory, Theory of Planned Behavior, and Adult Attachment Theory in explaining sexual risks among adolescents.

\section{Healthy Sex Attitudes Protect against Sexual Risk}

The replicated findings demonstrate that healthy sex attitudes are protective. When sexually experienced adolescents hold healthy attitudes about sexual decisions and behavior, they have fewer sexual partners, have their first sexual experience after early adolescence, and know their current sexual partners longer. These important findings highlight that adolescents are capable of managing inherent risks of sexual behaviors and engage in lower risk-taking when 
their attitudes emphasize having sex within emotionally committed relationships (Harden, 2014; Tolman \& McClelland, 2011).

Healthy sex attitudes also were related to lower sex frequency and intervened in the association between avoidant attachment and frequency of sex. This finding along with the replicated findings of healthy sex attitudes intervening in the relationship between avoidant attachment and other sexual risk indicators (i.e., number of sexual partners and length of knowing one's sexual partner) suggest that healthy attitudes about sex helps negate the influence of avoidant attachment on sexual risk-taking activities. Cohesively, these findings further support the protective nature of healthy sex attitudes and fit with past research showing that endorsement of healthy sex attitudes is related to less engagement in sexual risk-taking (Bersamin et al., 2006; McElwain et al., 2015). Taken together, healthy sex attitudes are associated with lower sexual risk and support expectations of the current study.

\section{Factors Associated with Greater Sexual Risk-Taking}

\section{Constraining Relationship Beliefs}

As expected, higher endorsement of constraining relationship beliefs was associated with greater sexual risk for adolescents, however, patterns found for constraining relationship beliefs did not replicate across cohorts. Higher constraining relationship beliefs were associated with less condom use (cohort 1), but also with greater seriousness of the relationship and greater frequency of sex (cohort 2). The findings for lower condom use and greater frequency of sexual activity are consistent with previous research indicating that constraining relationship beliefs influence involvement in sexual behaviors that put adolescents at risk for negative consequences (e.g., Gebhardt et al., 2003; Ott et al., 2006). At first glance, the positive association between constraining beliefs and relationship seriousness may suggest that such beliefs also serve as a 
protective factor. This finding also overlaps with Sprecher and Metts (1999) showing that such beliefs are related to more commitment to one's partner. However, an alternative explanation may be that some adolescents become committed too early in the relationship elevating their risk. Adolescents who endorse constraining relationship beliefs are more likely to idealize their partner, potentially viewing their dating relationships as "serious" or committed, regardless of what their partners believe. This notion coincides with past findings indicating that some adolescents have sex hoping to become exclusive with their partner (Manning et al., 2006) and may have unprotected sex to build intimacy in their romantic relationship (Gebhardt et al., 2003). Future studies will need to examine both partners' reports of their perceptions of the relationship to investigate this concept more fully.

\section{Romantic Attachment Insecurity}

The replicated findings showed that romantic attachment insecurity affects sexual risk, supporting the use of Adult Attachment Theory to help explain sexual risk-taking among adolescents. Specifically, being higher in avoidant attachment was associated with less commitment to a sexual partner. Moreover, when adolescents were more avoidant, they held lower healthy sex attitudes which was related to less time knowing the sexual partner and having a higher number of sexual partners. Although not fully replicated, avoidant attachment also was directly associated with sexual debut at a younger age and knowing the current sexual partner for a shorter time (cohort 2). Furthermore, condom use was greater when adolescents had a stronger avoidant attachment (cohort 1), consistent with Feeney et al. (2000) showing avoidant adolescent males are more likely to use condoms. Although adolescents higher in attachment avoidance may devalue intimacy and commitment within relationships, they may nevertheless practice some measures to avoid undesired consequences, such as pregnancy. Such behavior may still be means 
to avoid intimacy with a partner, as pregnancy might require an adolescent to commit reluctantly to a partner. Overall, the collective findings reinforce the assumption that adolescents higher in attachment avoidance are less likely to develop emotional intimacy with a sexual partner and may be fearful of commitment (Bartholomew, 1990; Bartholomew \& Horowitz, 1991; Olmstead, 2020; Schachner \& Shaver, 2004), and are more likely to have sex motivated by losing their virginity rather than intimacy (Tracy et al., 2003).

For adolescents higher in anxious attachment, our findings show a higher likelihood to have sex for the first time at a younger age (cohort 1) and a lower likelihood to use a condom during sex (direct association found in cohort 2; indirect association through constraining relationship beliefs found in cohort 1). Adolescents higher in anxious attachment may view sex as means to feel emotionally valued and to express love to their partner (Schachner \& Shaver, 2004; Tracy et al., 2003). They also may have greater dependence on the relationship (Bartholomew, 1990; Bartholomew \& Horowitz, 1991), may have sex to avoid losing their partner (Tracy et al., 2003), and thus may be more likely to give in to their partner's demands, increasing negative risks to their well-being by having sex at a young age or not using a condom.

In summary, romantic attachment insecurity was directly or indirectly associated with all six of the sexual risk indicators examined. The dimensions of avoidant and anxious attachment were examined as separate constructs, which allowed for elucidation of how they individually and collectively influence sexual risks among adolescents. In instances of indirect associations, avoidant attachment worked through healthy sex attitudes and constraining relationship beliefs to predict sexual risks. Replicated across cohorts, avoidant attachment was associated with less healthy attitudes toward sex which predicted greater sexual risks. However, in cohort 1 , avoidant attachment also was associated with lower constraining relationship beliefs which predicted 
more condom use. Attachment avoidance may reduce adolescents' idealization of romantic relationships (Pittman et al., 2011; Schachner \& Shaver, 2004) and, in that way, reduce engagement in risk-taking to please a partner. However, our collective findings suggest that adolescents with greater attachment avoidance may engage in sexual risk-taking to meet sexual rather than emotional needs.

\section{Limitations and Future Directions}

The present study makes several meaningful contributions to the literature; however, it is not without limitations. First, not all patterns were replicated across cohorts. This may be due to the demographic differences between the cohorts. Adolescents in the second cohort were more likely to be younger, to receive free/reduced lunch, and to be part of an ethnic minority group. Additionally, adolescents in cohort 2 engaged more extensively in sexual risk-taking than cohort 1 adolescents. On average, these adolescents had sex for the first time at a younger age, were in less serious relationships, had more sexual partners, and endorsed fewer healthy attitudes about sex. This aligns with past studies indicating adolescents who share these demographics are more likely to engage in risky sexual behaviors (Harris et al., 2000; Manning et al., 2000, 2005, 2006). Future studies should test similar models across diverse samples of adolescents to determine how demographic variables may matter for variability in sexual risk indicators and their associations with romantic attachment security and beliefs about relationships and attitudes about sexual activity.

Although findings of the present study support the argument that romantic attachment insecurity, constraining relationship beliefs, and healthy sex attitudes may work as risk and protective factors, this was not the case for all the sexual risk indicators. For instance, healthy sex attitudes did not predict condom use for either cohort. Regardless of whether they endorse 
healthy sex attitudes, adolescents have varied reasons for not using condoms. Whereas some adolescents do not use condoms because they desire to please their partners or they view using condoms negatively, other adolescents may choose not to use condoms once they are in serious, committed relationships that they believe are exclusive and therefore not a risk for STIs; they also may be using alternative means for birth control. Future research should explore this variability in adolescents' reasoning and condom use decisions.

Although the association between number of sexual partners and attachment avoidance was indirect through healthy sex attitudes, attachment anxiety had no association with the number of sexual partners. Although anxious attachment has shown a positive association with number of sexual partners in adult samples (Bogaert \& Sadava, 2002), this may not be evident yet in adolescence. Alternatively, high scores on anxious attachment emphasizes overcommitment to the relationship (Bartholomew, 1990; Bartholomew \& Horowitz, 1991). Thus, having many sexual partners may be undesirable for adolescents, including those higher in anxious attachment, seeking to commit to one significant other. Furthermore, holding constraining relationship beliefs refers to an ideology of one being meant for only one partner (e.g., "There is one true love out there who is right for me to marry") (Cobb et al., 2003). While some adolescents endorsing constraining relationship beliefs may not limit their sexual exploration to their ultimate partner choice, others may refrain from sexual activity until they find someone they believe is their one and only. This variability would diminish the overall strength of the association between constraining relationship beliefs and number of sexual partners. Additional research could explore how adolescents connect their sexual behaviors with these beliefs. 
The cross-sectional design of this study does not permit determination of temporal order in the identified patterns. Future studies using a longitudinal design could examine whether prior romantic attachment insecurity influences subsequent beliefs and attitudes about relationships and sex and whether such beliefs and attitudes explain concurrent and future sexual risk among adolescents and young adults. It also may be valuable for future research to examine the identified patterns among adolescents in casual dating relationships as such relationships have implications for romantic partnering in early adulthood (Olmstead, 2020). Romantic attachment insecurity may relate to sexual experiences differently among adolescents who are not in committed partnerships (Szielasko et al., 2013). Additionally, the community sample of the present study was collected in a conservative southern state, limiting the kinds of sexual activity assessed. It will be important to examine whether the identified risk and protective factors of the present study influence adolescents' engagement in other risky sexual activities associated with oral and anal sex, and it will be important to include additional predictors found to be associated with adolescent sexual risk-taking such as alcohol/substance use and quality of relationships with parents (American College of Health Association, 2009; Hutchinson et al., 2003; Olmstead, 2020).

In summary, findings of the present study with demographically diverse adolescents using a test-replication approach contribute to the literature by indicating that adolescents' insecurities, beliefs, and attitudes help explain different aspects of sexual risk-taking. Specifically, these findings stress the need to promote healthy attitudes about sex for adolescents to help them avoid engaging in sexual risk-taking. The results also suggest that constraining relationship beliefs should be addressed to prevent adolescents from engaging in sexual activities for the wrong reasons. Additionally, adolescents' romantic attachment insecurity makes them 
susceptible to engaging in sexual risk-taking, but the specific risk-taking varies according to whether they are higher in avoidance or anxiety due to differing reasons for engaging in risktaking. Adolescent sexual health promotion and interventions should not only focus on factors that influence the potential negative psychological and health outcomes of sexual risk-taking, but also on developing healthy sex attitudes and demystifying constraining relationship beliefs. In order to aid in the reduction of potentially detrimental risk-taking among sexually experienced adolescents, research and practice should consider comprehensive approaches that address adolescents past experiences, beliefs about relationships, and sex attitudes. 


\section{References}

Ajzen, I. (1985). From intentions to actions: A theory of planned behavior. In J. Kuhl \& J. Beckman (Eds.), Action-control: From cognition to behavior (pp. 11-39). Heidelberg: Springer.

American College Health Association. (2009). National College Health Assessment 2008 Reference Group Data Report. Journal of American College Health, 57(5), 477-488.

American Psychological Association. (2002). Developing adolescents: A reference for professionals. Retrieved from https://www.apa.org/pi/families/resources/develop.pdf

Bartholomew, K. (1990). Avoidance of intimacy: An attachment perspective. Journal of Social and Personal Relationships, 7, 147-178. https://doi.org/10.1177/0265407590072001

Bartholomew, K., \& Horowitz, L.M. (1991). Attachment styles among young adults: A test of a four-category model. Journal of Personal and Social Psychology, 61, 226-244. https://doi.org/10.1037/0022-3514.61.2.226

Bentler, P. M., \& Bonnett, D. G. (1980). Significance tests and goodness of fit in the analysis of covariance structures. Psychological Bulletin, 88, 588-606. https://doi.org/10.1037/0033-2909.88.3.588

Bersamin, M. M., Walker, S., Fisher, D. A., \& Grube, J. W. (2006). Correlates of oral sex and vaginal intercourse in early and middle adolescence. Journal of Research on Adolescence, 16(1), 59-68. https://doi.org/10.1111/j.1532-7795.2006.00120.x

Bogaert, A. F., \& Sadava, S. (2002). Adult attachment and sexual behavior. Personal Relationships, 9, 191-204. https://doi.org/10.1111/1475-6811.00012

Bingham, C. R., \& Crockett, L.J. (1996). Longitudinal adjustment patterns of boys and girls experiencing early, middle and late sexual intercourse. Developmental Psychology, 32, 


\section{7-658. https://doi.org/10.1037/0012-1649.32.4.647}

Brennan, K. A., Clark, C. L., \& Shaver, P. R. (1998). Self-report measurement of adult attachment: An integrative overview. In J. A. Simpson, \& W. S. Rholes (Eds.), Attachment Theory and Close Relationships (pp. 46-76). New York: Guilford.

Centers for Disease Control and Prevention. (2018). Over half of U.S teens have had sexual Intercourse by age 18, new report shows. https://www.cdc.gov/nchs/pressroom/nchs_press_releases/2017/201706_NSFG.htm

Chilman, C. (1990). Promoting Healthy Adolescent Sexuality. Family Relations, 39(2), 123-131. https://doi.org/10.2307/585712

Claxton, S. E., van Dulmen, M. H. M. (2013). Casual sexual relationships and experiences in emerging adulthood. Emerging Adulthood, 1(2), 138-150. https://doi.org/10.1177/2167696813487181

Cobb, N. P., Larson, J. H., \& Watson, W. L. (2003). Development of the attitudes about romance and mate selection scale. Family Relations, 52(3), 222-231. https://doi.org/10.1111/j.1741-3729.2003.00222.x

Collins, W.A. (2003). More than myth: The developmental significance of romantic relationships during adolescence. Journal of Research on Adolescence, 13, 1-24. https://doi.org/10.1111/1532-7795.1301001

Collins, W. A., Welsh, D. P., \& Furman, W. (2009). Adolescent romantic relationships. Annual Review of Psychology, 60, 631-652. https://doi.org.10.1146/annurev.psych.60.110707.163459 
Connolly, J., \& McIsaac, C. (2011). Romantic relationships in adolescence. In M. K. Underwood \& L. H. Rosen (Eds.), Social development: Relationships in infancy, childhood, and adolescence (pp. 180-203). New York, NY: The Guilford Press.

Costa, F. M., Jessor, R., Donovan, J.E., \& Fortenberry J.D. (2017). Understanding early initiation of sexual intercourse in adolescence. In R. Jessor (Ed.), Problem Behavior Theory and Adolescent Health. Advancing Responsible Adolescent Development (pp. 297-323). Cham, Switzerland: Springer.

Cubbins, L. A., \& Tanfer, K. (2000). The influence of gender on sex: A study of men's and women's self-reported high-risk sex behavior. Archives of Sexual Behavior, 29(3), 229257. https://doi.org/10.1023/A:1001963413640

Davis, D., Shaver, P. R., \& Vernon, M. L. (2004). Attachment style and subjective motivations for sex. Personality and Social Psychology Bulletin, 30, 10761090. https://doi.org/10.1177/0146167204264794

Driesmans, K., Vandenbosch, L., \& Eggermont, S. (2016). True love lasts forever: The influence of a popular teenage movie on Belgian girls' romantic beliefs. Journal of Children and Media, 10(3), 304-320. https://doi.org/10.1080/17482798.2016.1157501

Feeney, J. A., Kelly, L., Gallois, C., Peterson, C., \& Terry, D. J. (1999). Attachment style, assertive communication, and safer-sex behavior 1. Journal of Applied Social Psychology, 29, 1964-1983. https://doi.org/10.1111/j.1559-1816.1999.tb00159.x

Feeney, J. A., Peterson, C., Gallois, C., \& Terry, D. J. (2000). Attachment style as a predictor of sexual attitudes and behavior in late Adolescence. Psychology \& Health, 14, 1105-1122. https://doi.org/10.1080/08870440008407370

Fortunato, L., Young, A. M., Boyd, C. J., \& Fons, C. E. (2010). Hook-up sexual experiences and 
problem behaviors among adolescents. Journal of Child \& Adolescent Substance Abuse, 19, 261-278. https://doi.org/10.1080/1067828X.2010.488965

Furman, W., \& Simon, V. A. (1999). Cognitive representations of adolescent romantic relationships. The development of romantic relationships in adolescence, 75-98. New York: Cambridge University Press.

Gardner, S. P., Giese, K., \& Parrott, S. M. (2004). Evaluation of the Connections: Relationships and marriage curriculum. Family Relations, 53(5), 521-527. https://doi.org/10.1111/j.0197-6664.2004.00061.x

Gebhardt, W. A., Kuyper, L., \& Greunsven, G. (2003). Need for intimacy in relationships and motives for sex as determinants of adolescent condom use. Journal of Adolescent Health, 33, 154-164. https://doi.org/10.1016/S1054-139X(03)00137-X

Harden, K. P. (2014). A sex-positive framework for research on adolescent sexuality. Perspectives on Psychological Science, 9, 455-469. https://doi.org/10.1177/1745691614535934

Harlow, L. L. (2014). The essence of multivariate thinking: Basic themes and methods. Abingdon, UK: Routledge.

Harris, K. M., Duncan, G. J., \& Boisjoly, J. (2002). Evaluating the role of "nothing to lose" attitudes on risky behavior in adolescence. Social Forces, 80(3), 1005-1039. https://doi.org/10.1353/sof.2002.0008

Hutchinson, M. K., Jemmott, J. B., Sweet Jemmott L., Braverman, P., \& Fong, G. T. (2003). The role of mother-daughter sexual risk communication in reducing sexual risk behaviors among urban adolescent females: a prospective study. Journal of Adolescent Health. 33(2), 98-107. https://doi.org/10.1016/S1054-139X(03)00183-6 
IBM Corp. (2018). IBM SPSS statistics for Windows, version 26.0. Armonk, NY: IBM Corp.

Jessor, R. (1991). Risk behavior in adolescence: A psychosocial framework for understanding and action. Journal of Adolescent Health, 12, 597-605. https://doi.org/10.1016/1054-139X(91)90007-K

Jones, J.D., Fraley, C.R., Ehrlich, K.B., Stern, J.A., Lejuez, C.W., Shaver, P.R., \& Cassidy, J. (2018). Stability of attachment style in adolescence: An empirical test of alternative developmental processes. Child Development, 89, 872-880. https://doi.org/10.1111/cdev.12775

Kahn, N. \& Halpern, C. T. (2018). Associations between partners of sexual initiation, sexual partnering, and sexual health outcomes from adolescence to early adulthood. Archives of Sexual Behavior, 47, 1791-1810. https://doi.org/10.1007/s10508-018-1176-9

Kerpelman, J., Pittman, J., Adler-Baeder, F., Eryigit, S., \& Paulk, A. (2009). Evaluation of a statewide youth-focused relationships education curriculum. Journal of Adolescence, 32, 1359-1370. https://doi.org/10.1016/j.adolescence.2009.04.006

Kerpelman, J., Pittman, J., Adler-Baeder, F., Stringer, K., Eryigit, Saint-Eloi Cadely, H. \& Harrell-Levy, M. (2010). What adolescents bring to and learn from relationship education classes: Does social address matter? Journal of Couple \& Relationship Therapy, 9, 95-112. https://doi.org/10.1080/15332691003694877

Kerpelman, J. L., Pittman, J. F., Saint-Eloi Cadely, H., Tuggle, F. J., Harrell-Levy, M. K., \& Adler-Bader, F. M. (2012). Identity and intimacy during adolescence: Connections among identity styles, romantic attachment, and identity commitment. Journal of Adolescence, 35(6), 1427-1439. https://doi.org/10.1016/j.adolescence.2012.03.008

Kim, H. M., \& Miller, L.C. (2020). Are insecure attachment styles related to risky sexual 
behavior: A meta-analysis. Health Psychology, 39, 46-57. http://dx.doi.org/10.1037/hea0000821

Kline, R. B. (2016). Principles and practice of structural equation modeling. 4th ed. New York, NY: The Guilford Press.

Kochendorfer, L. B., \& Kerns, K. A. (2017). Perceptions of parent-child attachment relationships and friendship qualities: Predictors of romantic relationship involvement and quality in adolescence. Journal of Youth and Adolescence, 46(5), 1009-1021. https://doi.org/10.1007/s10964-017-0645-0

Kochendorfer, L. B., \& Kerns, K. A. (2020). A meta-analysis of friendship qualities and romantic relationship outcomes in adolescence. Journal of Research on Adolescence, 30 , 4-25. https://doi.org/10.1111/jora.12505

Larson, J. H. (1992). "You're my one and only": Premarital counseling for unrealistic beliefs about mate selection. American Journal of Family Therapy, 20, 242-253. https://doi.org/10.1080/01926189208250893

Lemelin, C., Lussier, Y., Sabourin, S., Brassard, A., \& Naud, C. (2014). Risky sexual behaviours: The role of substance use, psychopathic trains, and attachment security among adolescents and young adults in Quebec. The Canadian Journal of Human Sexuality, 23, 189-199. https://doi.org/10.3138/cjhs.2625

Letcher, A., \& Slesnick, N. (2014). Early relationships of adolescents: Evaluation and observation of romantic attachment and risk behavior. Journal of Social and Personal Relationships, 31(3), 366-383. https://doi.org/10.1177/0265407513496368

Ma, Y., Pittman, J. F., Kerpelman, J. L., \& Adler-Baeder, F. (2014). Relationship education and classroom climate impact on adolescents' standards for partners/relationships. Family 
Relations, 63(4), 453-468. https://doi.org/10.1111/fare.12084

MacDonald, T.K., McKenna, C., \& Mouck, L.C. (2016). The person and the partner: Individual differences moderate the relationship between partner feedback and condom use. AIDS and Behavior, 20, 185-196. https://doi.org/10.1007/s10461-015-1153-4

Madsen, S. D., \& Collins, W. A. (2011). The salience of adolescent romantic experiences for romantic relationship qualities in young adulthood. Journal of Research on Adolescence, 21(4), 789-801. https://doi.org/10.1111/j.1532-7795.2011.00737.x

Manning, W. D., Giordano, P. C., \& Longmore, M. A. (2006). Hooking up: The relationship contexts of "nonrelationship" sex. Journal of Adolescent Research, 21(5), 459-483. https://doi.org/10.1177/0743558406291692

Manning, W. D., Longmore, M. A., Copp, J., \& Giordano, P. C. (2014). The complexities of adolescent dating and sexual relationships: Fluidity, meaning(s), and implications for young adults' well-being. In E. S. Lefkowitz \& S. A. Vasilenko (Eds.), Positive and negative outcomes of sexual behaviors. New Directions for Child and Adolescent Development, 144, 53-69.

Manning, W. D., Longmore, M. A., \& Giordano, P. C. (2000). The relationship context of contraceptive use at first intercourse. Family Planning Perspectives, 32(3), 104-110. https://doi.org.10.2307/2648158

Manning, W. D., Longmore, M. A., \& Giordano, P. C. (2005). Adolescents' involvement in nonromantic sexual activity. Social Science Research, 34(2), 384-407. https://doi.org/10.1016/j.ssresearch.2004.03.001

McEachan, R. R. C., Conner, M., Taylor, N. J., \& Lawton, R. J. (2011). Prospective prediction of health-related behaviours with the Theory of Planned Behavior: A meta-analysis. Health 
Psychology Review, 5, 97-144. https://doi.org/10.1080/17437199.2010.521684

McElwain, A. D., Kerpelman, J. L., \& Pittman, J. F. (2015). The role of romantic attachment security and dating identity exploration in understanding adolescents' sexual attitudes and cumulative sexual risk-taking. Journal of Adolescence, 39, 70-81. https://doi.org/10.1016/j.adolescence.2014.12.005

McNeill, A. D., Miller, M., Stancil, S., \& Randell, K. (2020). 202. Improving sexual and reproductive health care access for adolescents with housing instability. Journal of Adolescent Health, 66(2), S102-S103. https://doi.org/10.1016/j.jadohealth.2019.11.205

Mitchell, C. E., Tanner, J. F., \& Raymond, M. A. (2004). Adolescents' perceptions of factors influencing values and sexual initiation: Implications of social marketing initiatives. Journal of Nonprofit \& Public Sector Marketing, 12(2), 29-49. https://doi.org/10.1300/J054v12n02_02

Misovich, S. J., Fisher, J. D., \& Fisher, W. A. (1997). Close relationships and elevated HIV risk Behavior: Evidence and possible underlying psychological processes. Review of General Psychology, 1(1), 72-107. https://doi.org/10.1037/1089-2680.1.1.72.

Montgomery, M. J. (2005). Psychosocial intimacy and identity: From early adolescence to emerging adulthood. Journal of Adolescent Research, 20(3), 346-374. https://doi.org/10.1177/0743558404273118

Muetzelfeld, H., Megale, A., \& Friedlander, M.L. (2020). Problematic domains of romantic relationships as a function of attachment insecurity and gender. Australian and New Zealand Journal of Family Therapy, 41, 80-90. https://doi.org/10.1002/anzf.1401

Muthén, L. K., \& Muthén, B. O. (1998-2012). Mplus: Statistical analysis with latent variables. User's guide. Los Angeles, CA: Muthén \& Muthén. 
Olmstead, S. B. (2020). A decade review of sex and partnering in adolescence and young adulthood. Journal of Marriage and Family, 82, 769-795. https://doi.org/10.1111/jomf.12670

Ott, M. A., Millstein, S. G., Ofner, S., \& Halpern-Felsher, B. L. (2006). Greater expectations: Adolescents' positive motivations for sex. Perspectives on sexual and reproductive health, 38(2), 84-89. https://doi.org/10.1363/3808406

Pittman, J. F., Keiley, M. K., Kerpelman, J. L., \& Vaughn, B. E. (2011). Attachment, identity, and intimacy: Parallels between Bowlby's and Erikson's paradigms. Journal of Family Theory \& Review, 3, 32-46. https://doi.org/10.1111/j.1756-2589.2010.00079.x

Prendergast, L. E., Tombourou, J. W., McMorris, B. J., \& Catalano, R. F. (2019). Outcomes of early adolescent sexual behavior in Australia: Longitudinal findings in young adulthood. Journal of Adolescent Health, 63, 516-522. https://doi.org/10.1016/j.jadohealth.2018.10.006

Roisman, G. I. (2009). Adult attachment: Toward a rapprochement of methodological cultures. Current Directions in Psychological Science, 18(2), 122-126. https://doi.org/10.1111/j.1467-8721.2009.01621.x

Roisman, G. I., Booth-LaForce, C., Cauffman, E., Spieker, S., \& The NICHD Early Child Care Research Network. (2009). The developmental significance of adolescent romantic relationships: Parents and peer predictors of engagement and quality at age 15. Journal of Youth Adolescence, 38, 1294-1303. https://doi.org/10.1007/s10964-008-9378-4

Saint-Eloi Cadely, H., Kerpelman, J. L., \& Pittman, J. F. (2018). Connections among identity, 
attachment, and psychological dating aggression during adolescence. Identity: An International Journal of Theory and Research, 18(1), 44-59. https://doi.org/10.1080/15283488.2017.1410158.

Schachner, D. A., \& Shaver, P. R. (2004). Attachment dimensions and sexual motives. Personal relationships, 11, 179-195. https://doi.org/10.1111/j.1475-6811.2004.00077.x

Sprecher, S., \& Metts, S. (1999). Romantic beliefs: Their influence on relationships and patterns of change over time. Journal of Social and Personal Relationships, 16(6), 834-851. https://doi.org/10.1177\%2F0265407599166009

Stackert, R. A., \& Bursik, K. (2003). Why am I unsatisfied? Adult attachment style, gendered irrational relationship beliefs, and young adult romantic relationship satisfaction. Personality and Individual Differences, 34, 1419-1429. https://doi.org/10.1016/S0191$\underline{8869(02) 00124-1}$

Stevens, C.J., Gillman, A.S., Gardiner, C.K., Montanaro, E. A., Bryan, A.D., \& Conner, M. (2019). Feel good now or regret it later? The respective roles of affective attitudes and anticipated affective reactions for explaining health-promoting and health risk behavioral intentions. Journal of Applied Social Psychology, 49, 331-348. https://doi.org/10.1111/jasp.12584

Strachman, A., \& Impett, E. A. (2009). Attachment orientations and daily condom use in dating relationships. Journal of Sex Research, 46(4), 319-329. https://doi.org/10.1080/00224490802691801

Szielasko, A. L., Symons, D. K., \& Price, E. L. (2013). Development of an attachment-informed measure of sexual behavior in late adolescence. Journal of Adolescence, 36, 361-370. https://doi.org/10.1016/j.adolescence.2012.12.008 
Tolman, D. L., \& McClelland, S. I. (2011). Normative sexuality development in adolescence: A decade in review, 2000-2009. Journal of Research on Adolescence, 21(1), 242-255. https://doi.org/10.1111/j.1532-7795.2010.00726.x

Tracy, J. L., Shaver, P. R., Albino, A. W., \& Cooper, M. L. (2003). Attachment styles and adolescent sexuality. In P. Florsheim (Ed.), Adolescent romantic relations and sexual behavior: Theory, research, and practical implications (pp. 137-159). Mahwah, NJ, US: Lawrence Erlbaum Associates Publishers.

Turner, L.A., \& Langhinrichsen-Rohling, J. (2011). Attachment, relationship beliefs, and partner-specific assertiveness and psychological aggression among college students. Partner Abuse, 2, 387-403. https//doi.org.10.1891/1946-6560.2.4.387 
Table 1. Correlations between insecure attachment, healthy sex attitudes, constraining relationship beliefs, and sexual risk indicators.

\begin{tabular}{|c|c|c|c|c|c|c|c|c|c|c|}
\hline Variable & 1 & 2 & 3 & 4 & 5 & 6 & 7 & 8 & 9 & 10 \\
\hline 1. Anxious & - & $.28^{* * * *}$ & .02 & $.17^{* * * *}$ & .05 & .00 & $-.09^{*}$ & -.02 & .01 & .04 \\
\hline 2. Avoidant & $.25^{* * *}$ & - & $-.12^{* *}$ & $-.23^{* * *}$ & $-.13^{* *}$ & $.13^{* *}$ & .01 & $-.14^{* * *}$ & $-.19^{* * * *}$ & -.04 \\
\hline 3. Sex Attitudes & .03 & $-.17^{* * *}$ & - & $.25^{* * *}$ & $.24^{* * * *}$ & $-.27^{* * *}$ & -.03 & $.30^{* * *}$ & $.19^{* * *}$ & $-.20^{* * *}$ \\
\hline 4. Beliefs & .07 & $-.26^{* * *}$ & $.26^{* * *}$ & - & $.12^{* *}$ & $-.14^{* *}$ & -.04 & $.12^{* *}$ & $.23^{* * *}$ & .05 \\
\hline 5. $1^{\text {st }}$ Sex Age & -.04 & $-.09^{*}$ & $.23^{* * *}$ & .07 & - & $-.46^{* * *}$ & .03 & $.15^{* *}$ & $.15^{* * *}$ & -.05 \\
\hline 6. \# of partners & .03 & $.10^{* *}$ & $-.27^{* * *}$ & $-.12^{* *}$ & $-.44^{* * *}$ & - & -.02 & $-.21^{* * * *}$ & $-.13^{* *}$ & $.14^{* * *}$ \\
\hline 7. Condom Use & -.03 & $.10^{* *}$ & -.06 & $-.12^{* *}$ & .03 & -.03 & - & .04 & -.03 & $-.18^{* * *}$ \\
\hline $\begin{array}{l}\text { 8. Length w/ } \\
\text { partner }\end{array}$ & .03 & -.06 & $.27^{* * *}$ & $.09^{* *}$ & $.13^{* * *}$ & $-.18^{* * *}$ & $.08^{*}$ & - & $.24^{* * *}$ & -.04 \\
\hline $\begin{array}{l}\text { 9. Serious } \\
\text { relationship }\end{array}$ & -.03 & $-.25^{* * *}$ & $.21^{* * *}$ & $.15^{* * *}$ & $.19^{* * *}$ & $-.11^{* *}$ & -.06 & $.28^{* * *}$ & - & $.24^{* * *}$ \\
\hline $\begin{array}{l}\text { 10. Sex } \\
\text { frequency }\end{array}$ & & & & & & & & & & - \\
\hline
\end{tabular}

Note. Correlations for cohort $1(N=878)$ appear in the lower left and cohort $2(N=759)$ in the upper right diagonals. Sex Attitudes = Healthy Sex Attitudes; Beliefs $=$ Constraining Relationship Beliefs; $1^{\text {st }}$ Sex Age $=$ Age at first sex.

${ }^{*} p<.05,{ }^{* *} p<.01,{ }^{* * *} p<.001$. 
Table 2. Differences across cohorts in demographics and reports of insecure attachment dimensions,

healthy sex attitudes, constraining relationship beliefs, and sexual risk indicators $(N=1,637)$.

$\begin{array}{cc}\text { Cohort } 1 & \text { Cohort } 2 \\ (n=878 ; 53.6 \%) & (n=759 ; 46.4 \%)\end{array}$

\section{Cross-Tabulation Results}

Sex

Male $(48.3 \%)^{+}$

Female $(49.2 \%)^{+}$

Race***

Whites $(39.3 \%)^{+}$

Minorities $(60.2 \%)^{+}$

Free/Reduced Lunch ${ }^{* * *}$

No $(37.9 \%)^{+}$

Yes $(58.6 \%)^{+}$

\section{T-Test Results}

$\operatorname{Age}^{* * *}$

Insecure Attachment

Anxious Dimension ${ }^{* *}$

Avoidant Dimension

Sex Attitudes**

Beliefs $^{* * *}$

Risky Sexual Engagement

1st Sex Age **

\# of Sexual Partners*

Condom Use

Length w/Partner

Serious Relationship ${ }^{* *}$
$47.7 \%$

$52.3 \%$

$51.7 \%$

$48.3 \%$

$46.5 \%^{\circ}$

$53.5 \%^{\mathrm{u}}$

$31.5 \%^{\mathrm{u}}$

$68.5 \%^{\circ}$

$44.6 \%{ }^{\circ}$

$55.4 \%$ u

$33.3 \%^{\mathrm{u}}$

$66.7 \%^{\circ}$

$M(S D)$

$M(S D)$

$16.50(1.06)$

$15.78(.95)$

$2.70(.85)$

$2.09(.72)$

$2.59(.84)$

$2.12(.71)$

$3.80(.78)$

$3.68(.81)$

$3.71(.77)$

$3.58(.77)$

$14.17(1.41)$

$13.94(1.48)$

$2.50(1.50)$

2.67 (1.52)

3.65 (1.59)

3.78 (1.54)

4.18 (1.20)

2.83 (1.36)

2.61 (1.38)

Note. ${ }^{+}$Percentages of the total sample. ${ }^{\circ}$ (Overrepresented), ${ }^{\text {u}}($ Underrepresented). Sex Attitudes = Healthy Sex Attitudes; Beliefs = Constraining Relationship Beliefs; 1st Sex Age = Age at first sex . ${ }^{*} p<.05,{ }^{* *} p<.01,{ }^{* * *} p<.001$. 
Table 3. Cohort 1: Standardized and unstandardized parameter estimates, indirect effects, $R$-squares, and fit statistics for insecure attachment dimensions, healthy sex attitudes, and constraining relationship beliefs predicting sexual risk indicators $(N=878)$.

\begin{tabular}{|c|c|c|c|c|c|c|c|c|c|c|c|c|c|c|c|}
\hline & \multicolumn{3}{|c|}{ Age at First Sex } & \multicolumn{3}{|c|}{ Number of Sex Partners } & \multicolumn{3}{|c|}{ Condom Use } & \multicolumn{3}{|c|}{ Length w/ Partner } & \multicolumn{3}{|c|}{ Serious Relationship } \\
\hline & $B$ & (S.E) & $\beta$ & $B$ & (S.E) & $\beta$ & $B$ & (S.E) & $\beta$ & $B$ & (S.E) & $\beta$ & $B$ & (S.E) & $\beta$ \\
\hline Anxious Dimension & -.11 & $(.06)$ & $-.07^{\sim}$ & .07 & $(.06)$ & .04 & -.06 & $(.07)$ & -.03 & .01 & $(.05)$ & .01 & -.00 & $(.06)$ & -.00 \\
\hline Avoidant Dimension & -.03 & $(.07)$ & -.01 & .02 & $(.07)$ & .01 & .16 & $(.08)$ & $.07^{\sim}$ & -.02 & $(.06)$ & -.01 & -.42 & $(.07)$ & $-.22^{*}$ \\
\hline Sex Attitudes & .24 & $(.07)$ & $.13^{*}$ & -.42 & $(.07)$ & $-.22^{*}$ & -.00 & $(.08)$ & -.00 & .29 & $(.06)$ & $.19^{*}$ & .11 & $(.07)$ & .06 \\
\hline Beliefs & -.05 & $(.06)$ & -.03 & -.06 & $(.07)$ & -.03 & -.17 & $(.08)$ & $-.08^{*}$ & .00 & $(.06)$ & .00 & .05 & $(.06)$ & .03 \\
\hline Gender & .36 & $(.11)$ & $.13^{*}$ & -.10 & $(.12)$ & -.03 & -.04 & $(.13)$ & -.01 & .35 & $(.10)$ & $.15^{*}$ & .55 & $(.11)$ & $.20^{*}$ \\
\hline Race & -.57 & $(.10)$ & $-.20^{*}$ & .57 & $(.11)$ & $.19^{*}$ & .46 & $(.12)$ & $.14^{*}$ & -.05 & (.09) & -.02 & -.10 & $(.10)$ & -.03 \\
\hline Free/Reduced Lunch & -.06 & $(.10)$ & -.02 & .01 & $(.11)$ & .00 & -.19 & $(.12)$ & -.06 & -.07 & $(.09)$ & -.03 & .08 & $(.10)$ & .03 \\
\hline Age & $.34 \mathrm{a}$ & $(.04)$ & $.25^{*}$ & .21 & $(.05)$ & $.15^{*}$ & -.13 & $(.05)$ & $-.09^{*}$ & -.02 & $(.04)$ & -.01 & .11 & $(.04)$ & $.08^{*}$ \\
\hline \multicolumn{16}{|l|}{ Anxious Dimension } \\
\hline Total effects & -.11 & $(.06)$ & $-.07^{\sim}$ & .06 & $(.06)$ & .03 & -.08 & $(.07)$ & -.04 & .02 & $(.05)$ & .01 & .00 & $(.05)$ & .00 \\
\hline Total indirect effects & .00 & $(.01)$ & .00 & -.02 & $(.01)$ & -.01 & -.02 & $(.01)$ & $-.01^{\sim}$ & .01 & $(.01)$ & .00 & .01 & $(.01)$ & .00 \\
\hline \multicolumn{16}{|l|}{ Specific Indirect Effects } \\
\hline Sex Attitudes & .01 & $(.01)$ & .00 & -.01 & $(.01)$ & -.01 & .00 & $(.00)$ & .00 & .01 & $(.01)$ & .00 & .00 & $(.00)$ & .00 \\
\hline Beliefs & -.00 & $(.01)$ & -.00 & -.01 & $(.01)$ & -.00 & -.02 & $(.01)$ & $-.01^{\sim}$ & .00 & $(.01)$ & .00 & .00 & $(.01)$ & .00 \\
\hline \multicolumn{16}{|l|}{ Avoidant Dimension } \\
\hline Total effects & -.04 & $(.07)$ & -.02 & .10 & $(.07)$ & .05 & .21 & $(.08)$ & $.09^{*}$ & -.06 & $(.06)$ & -.03 & -.45 & $(.07)$ & $-.24^{*}$ \\
\hline Total indirect effects & -.02 & $(.02)$ & -.01 & .07 & $(.03)$ & $.04^{*}$ & .05 & $(.02)$ & $.02^{*}$ & -.04 & $(.02)$ & $-.02^{\sim}$ & -.03 & $(.02)$ & -.02 \\
\hline \multicolumn{16}{|l|}{ Specific Indirect Effects } \\
\hline Sex Attitudes & -.03 & $(.01)$ & $-.02^{*}$ & .06 & $(.02)$ & $.03^{*}$ & .00 & $(.01)$ & .00 & -.04 & $(.01)$ & $-.02^{*}$ & -.01 & $(.01)$ & -.01 \\
\hline Beliefs & .01 & $(.02)$ & .01 & .02 & $(.02)$ & .01 & .05 & $(.02)$ & $.02^{*}$ & -.00 & $(.02)$ & -.00 & -.01 & $(.02)$ & -.01 \\
\hline \multicolumn{16}{|l|}{ R-Squares } \\
\hline Sex Attitudes & .28 & & & & & & & & & & & & & & \\
\hline 1st Sex Age & .16 & & & & & & & & & & & & & & \\
\hline Number of Partners & .14 & & & & & & & & & & & & & & \\
\hline Condom Use & .04 & & & & & & & & & & & & & & \\
\hline Length w/ Partner & .09 & & & & & & & & & & & & & & \\
\hline Serious Rel. & .13 & & & & & & & & & & & & & & \\
\hline Beliefs & .14 & & & & & & & & & & & & & & \\
\hline
\end{tabular}

Note. Sex Attitudes = Healthy Sex Attitudes; Beliefs = Constraining Relationship Beliefs; 1 st Sex Age $=$ Age at first sex. $\sim p<.10,{ }^{*} p<.05$. 
Table 4. Cohort 2: Standardized and unstandardized parameter estimates, indirect effects, $R$-squares, and fit statistics for insecure attachment dimensions, healthy sex attitudes, and constraining relationship beliefs predicting sexual risk indicators $(N=759)$.

\begin{tabular}{|c|c|c|c|c|c|c|c|c|c|c|c|c|c|c|c|}
\hline & \multicolumn{3}{|c|}{ Age at First Sex } & \multicolumn{3}{|c|}{ Number of Sex Partners } & \multicolumn{3}{|c|}{ Condom Use } & \multicolumn{3}{|c|}{ Length w/ Partner } & \multicolumn{3}{|c|}{ Serious Relationship } \\
\hline & $B$ & (S.E) & $\beta$ & $B$ & (S.E) & $\beta$ & $B$ & (S.E) & $\beta$ & $B$ & (S.E) & $\beta$ & $B$ & (S.E) & $\beta$ \\
\hline Anxious Dimension & .04 & $(.06)$ & .02 & .04 & $(.07)$ & .02 & -.14 & $(.08)$ & $-.07^{\sim}$ & -.01 & $(.05)$ & -.00 & .00 & $(.07)$ & .00 \\
\hline Avoidant Dimension & -.18 & $(.08)$ & $-.08^{*}$ & .13 & $(.09)$ & .06 & .04 & $(.09)$ & .02 & -.17 & $(.06)$ & $-.11^{*}$ & -.27 & $(.08)$ & $-.14^{*}$ \\
\hline Sex Attitudes & .15 & $(.07)$ & $.08^{*}$ & -.41 & $(.08)$ & $-.22^{*}$ & .02 & $(.09)$ & .01 & .32 & $(.06)$ & $.23^{*}$ & .09 & $(.07)$ & .05 \\
\hline Beliefs & .03 & $(.07)$ & .02 & -.12 & $(.08)$ & -.06 & -.01 & $(.08)$ & -.00 & .02 & $(.06)$ & .02 & .27 & $(.07)$ & $.15^{*}$ \\
\hline Gender & .80 & $(.12)$ & $.27^{*}$ & -.21 & $(.13)$ & -.07 & -.23 & $(.14)$ & $-.08^{\sim}$ & .28 & $(.10)$ & $.12^{*}$ & .39 & $(.12)$ & $.14^{*}$ \\
\hline Race & -.40 & $(.11)$ & $-.12^{*}$ & .33 & $(.12)$ & $.10^{*}$ & .27 & $(.13)$ & $.08^{*}$ & .18 & $(.09)$ & $.07^{\sim}$ & -.09 & $(.11)$ & -.03 \\
\hline Free/Reduced Lunch & -.25 & $(.11)$ & $-.08^{*}$ & .17 & $(.12)$ & .05 & -.06 & $(.13)$ & -.02 & -.10 & $(.09)$ & -.04 & -.03 & $(.11)$ & -.01 \\
\hline Age & $.50 \mathrm{a}$ & $(.05)$ & $.32^{*}$ & .17 & $(.06)$ & $.11^{*}$ & -.01 & $(.06)$ & -.01 & .03 & $(.04)$ & .03 & .17 & $(.05)$ & $.12^{*}$ \\
\hline \multicolumn{16}{|l|}{ Anxious Dimension } \\
\hline Total effects & .05 & $(.06)$ & .03 & .02 & $(.07)$ & .01 & -.14 & $(.07)$ & $-.08^{\sim}$ & -.00 & $(.05)$ & -.00 & .06 & $(.06)$ & .04 \\
\hline Total indirect effects & .00 & $(.02)$ & .00 & -.02 & $(.02)$ & -.01 & -.00 & $(.02)$ & -.00 & -.00 & $(.02)$ & -.00 & .05 & $(.02)$ & $.03^{*}$ \\
\hline \multicolumn{16}{|l|}{ Specific Indirect Effects } \\
\hline Sex Attitudes & -.00 & $(.00)$ & -.00 & .01 & $(.01)$ & .00 & .00 & $(.00)$ & .00 & -.01 & $(.01)$ & -.00 & -.00 & $(.00)$ & -.00 \\
\hline Beliefs & .01 & $(.01)$ & -.00 & -.03 & $(.02)$ & -.01 & -.00 & $(.02)$ & -.00 & .00 & $(.01)$ & .00 & .06 & $(.02)$ & $.03^{*}$ \\
\hline \multicolumn{16}{|l|}{ Avoidant Dimension } \\
\hline Total effects & -.20 & $(.07)$ & $-.10^{*}$ & .20 & $(.08)$ & $.10^{*}$ & .04 & $(.09)$ & .02 & -.21 & $(.06)$ & $-.13^{*}$ & -.36 & $(.08)$ & $-.19^{*}$ \\
\hline Total indirect effects & -.02 & $(.02)$ & -.01 & .07 & $(.03)$ & $.03^{*}$ & .00 & $(.03)$ & .00 & -.04 & $(.02)$ & -.02 & -.09 & $(.02)$ & $-.05^{*}$ \\
\hline \multicolumn{16}{|l|}{ Specific Indirect Effects } \\
\hline Sex Attitudes & -.01 & $(.01)$ & -.01 & .04 & $(.02)$ & $.02^{*}$ & -.00 & $(.01)$ & -.00 & -.03 & $(.01)$ & $-.02^{*}$ & -.01 & $(.01)$ & -.00 \\
\hline Beliefs & -.01 & $(.02)$ & -.00 & .04 & $(.02)$ & .02 & .00 & $(.03)$ & .00 & -.01 & $(.02)$ & -.00 & -.08 & $(.02)$ & $-.04^{*}$ \\
\hline \multicolumn{16}{|l|}{ R-Squares } \\
\hline Sex Attitudes & .29 & & & & & & & & & & & & & & \\
\hline 1st Sex Age & .25 & & & & & & & & & & & & & & \\
\hline Number of Partners & .12 & & & & & & & & & & & & & & \\
\hline Condom Use & .02 & & & & & & & & & & & & & & \\
\hline Length w/ Partner & .12 & & & & & & & & & & & & & & \\
\hline Serious Rel. & .12 & & & & & & & & & & & & & & \\
\hline Beliefs & .15 & & & & & & & & & & & & & & \\
\hline
\end{tabular}

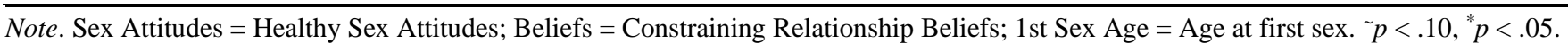


Figure 1. Hypothesized SEM model of attachment dimensions predicting sexual risk indicators through healthy sex attitudes and constraining relationship beliefs. Analyses controlled for gender, race, free/reduced lunch, and age.

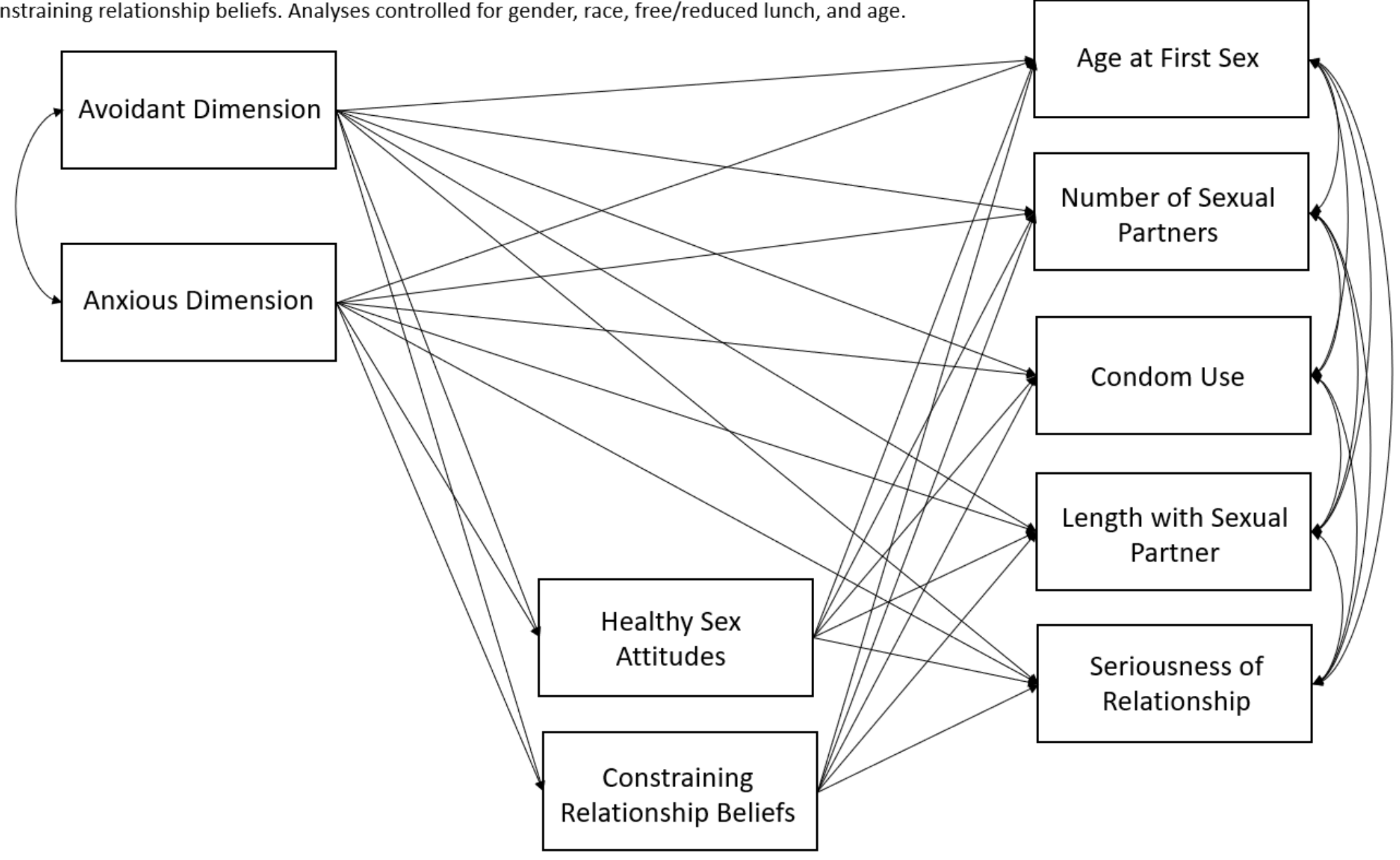

Note. An extended model for cohort 2 was fit with the inclusion of frequency of sex added as a sixth outcome variable. 